\title{
Encouraging MSK imaging research towards clinical impact is a necessity: opinion paper of the European Society of Musculoskeletal Radiology (ESSR)
}

\author{
Alberto Stefano Tagliafico ${ }^{1,2}$ (D) - David Wilson ${ }^{3} \cdot$ Luca Maria Sconfienza $^{4,5}$ - on behalf of the European Society of \\ Musculoskeletal Radiology (ESSR) Research Committee
}

Received: 17 January 2019 / Revised: 29 March 2019 / Accepted: 2 April 2019 / Published online: 6 May 2019

(C) European Society of Radiology 2019

\begin{abstract}
Radiology has not been spared in recent economic crises with a substantial reduction in the turnover of imaging equipment. These problems are exacerbated by increasing demand for healthcare across Europe. Therefore, using existing radiological services while rigorously following evidence-based guidelines might improve patient care. Thus, diagnostic pathways should be assessed not only for technical and diagnostic performance but also for their impact on medical and social outcome. In this paper, we report the advice of the Research Committee of ESSR on how we may guide musculoskeletal radiological research towards studies that have useful clinical impact. The ESSR Research Committee intends to encourage research with potential to influence treatment, patient outcome, and social impact.

Key Points

- Research in medical imaging has the potential to improve human health.

- High-level studies have the potential to place radiology at the pinnacle of quality in evidence-based practice.

- The ESSR Research Committee intends to encourage research with potential to influence treatment, patient outcome, and social impact.
\end{abstract}

Keywords Research · Diagnosis $\cdot$ Healthcare

\section{Abbreviations \\ ESR European Society of Radiology \\ ESSR European Society of Musculoskeletal Radiology}

Alberto Stefano Tagliafico and Luca Maria Sconfienza contribute equally.

Alberto Stefano Tagliafico

alberto.tagliafico@unige.it

1 University of Genova, Via Balbi 5, 16126 Genova, GE, Italy

2 AOU IRCCS Policlinico San Martino, Largo Rosanna Benzi 10, 16132 Genova, GE, Italy

3 St Luke's Radiology Ltd, Latimer Road, Headington, Oxford OX3 7PF, UK

4 Dipartimento di Scienze Biomediche per la Salute, Università degli Studi di Milano, Via Pascal 36, 20133 Milan, Italy

5 Unità Operativa di Radiologia Diagnostica ed Interventistica, IRCCS Istituto Ortopedico Galeazzi, Via Riccardo Galeazzi 4, 20161 Milan, Italy
Radiology has not been spared in recent economic crises with a substantial reduction in the turnover of imaging equipment [1]. These problems are exacerbated by increasing demand for healthcare across Europe. New developments in medical sciences and technology combine with an aging population to increase overall demand [1]. Current provision of imaging does not seem sustainable and practice is likely to be modified in the next few years. However, it is not axiomatic that these changes will lead to worse outcome. For example, there are many areas of medicine where not testing, not imaging, and not treating could result in better health outcomes [2]. Indeed, providing more services has not implied a direct improvement of health measures in some areas [3]. Thus, diagnostic pathways should be assessed not only for technical and diagnostic performance but also for their impact on medical and social outcome. John R. Thornbury advocated this concept in 1994, suggesting that radiologists should have a strong commitment not only in technology assessment but also in outcome research [4]. This should include a multidisciplinary approach involving the referring physicians and other key personnel in the research [4, 
Table 1 Hierarchy of studies on diagnostic tests. From reference [4] and from Sardanelli F, Di Leo G (2008) Biostatistics for radiologists. Springer, Milan, pp. 165-179

\begin{tabular}{ll}
\hline Level & Parameters under investigation \\
\hline $\begin{array}{l}\text { 6. Societal impact } \\
\text { 5. Patient outcomes }\end{array}$ & $\begin{array}{l}\text { Benefit-cost and cost-effectiveness analysis from a social perspective } \\
\text { Fraction of patients improved with the test compared with that of those improved without the test; difference in } \\
\text { morbidity between the patients with the test and those without the test; gain in quality-adjusted life years (QALYs) } \\
\text { obtained by the patients with the test compared with those without the test }\end{array}$ \\
4. Therapeutic impact & $\begin{array}{r}\text { Fraction of patients for whom the test is judged useful for treatment planning or for whom the treatment planning is } \\
\text { modified on the basis of the information supplied by the test }\end{array}$ \\
3. Diagnostic impact & $\begin{array}{r}\text { Fraction of patients for whom the test is judged useful for rendering the diagnosis or for whom the diagnosis is } \\
\text { substantially modified after the test; positive and negative likelihood ratios } \\
\text { 2. Diagnostic performance }\end{array}$ \\
$\begin{array}{l}\text { Sensitivity, specificity, accuracy, positive predictive value, negative predictive value, and receiver operator characteristic } \\
\text { (ROC) analysis; intraobserver, interobserver, and interstudy reproducibility }\end{array}$ \\
$\begin{array}{l}\text { Gray-scale range; modulation transfer function; sharpness; spatial resolution, in-plane (line pairs per mm, pixel size) and } \\
\text { through-the-plane (slice thickness), integrated in voxel size; signal-to-noise ratio; contrast resolution } \\
\text { (contrast-to-noise ratio); time resolution (images/s), etc. }\end{array}$ \\
\hline
\end{tabular}

5]. The mission and vision of the European Society of Musculoskeletal Radiology (ESSR) describes the development, distribution, and cost-effective implementation of stateof-the-art radiological concepts to benefit patients $[6,7]$.

In this paper, we present the opinion of the Research Committee of ESSR considering how we may guide musculoskeletal radiological research towards studies with an added clinical value.

According to Medina and Blackmore, only a third of imaging practice is supported by scientific evidence [8]. Other authors estimate that well-conducted randomized controlled trials, meta-analyses, or systematic reviews are available for less than $10 \%$ of standard imaging procedures $[9,10]$. An internal analysis of the ESSR 2008-2016 annual meetings concluded that most musculoskeletal radiological research falls into the two lower levels of the Thornbury scale
(Tables 1 and 2). Not surprisingly, only a few studies were likely to influence therapy, patient outcome, or social impact. The Thornbury scale is a one-way logical chain where a positive effect at any level generally implies a positive effect at lower levels but not vice versa [10]. Consequently, a new diagnostic technology with a positive impact on patient outcome may have better technical and diagnostic performances compared with standard technology. Conversely, there is no certainty that a radiologic test with a higher diagnostic performance results in better patient outcome [8-10]. The strong potential of musculoskeletal radiology to have clinical impact is demonstrated by those studies on interventional techniques or procedures (Tables 3 and 4). Interventional radiology has a pivotal role in patient care.

Indeed, the importance on patients' impact of musculoskeletal radiology may have been underestimated in the
Table 2 Number of abstracts according to the modified Thornbury scale per year

\begin{tabular}{llllllll}
\hline $\begin{array}{l}\text { Year of } \\
\text { ESSR } \\
\text { congress }\end{array}$ & $\begin{array}{l}\text { Total } \\
\text { number of } \\
\text { abstracts }\end{array}$ & $\begin{array}{l}\text { 1. Technical } \\
\text { performance }\end{array}$ & $\begin{array}{l}2 . \\
\text { Diagnostic } \\
\text { performance }\end{array}$ & $\begin{array}{l}\text { 3. } \\
\text { Diagnostic } \\
\text { impact }\end{array}$ & $\begin{array}{l}\text { 4. } \\
\text { Therapeutic } \\
\text { impact }\end{array}$ & $\begin{array}{l}\text { 5. Patient } \\
\text { outcomes }\end{array}$ & $\begin{array}{l}\text { 6. } \\
\text { Social } \\
\text { Impact }\end{array}$ \\
\hline 2008 & 35 & $14(40 \%)$ & $11(31 \%)$ & $2(6 \%)$ & $7(20 \%)$ & $1(3 \%)$ & - \\
2009 & 37 & $20(54 \%)$ & $10(27 \%)$ & $5(15 \%)$ & $1(3 \%)$ & $1(3 \%)$ & - \\
2010 & 42 & $20(48 \%)$ & $13(31 \%)$ & $3(7 \%)$ & $6(14 \%)$ & - & - \\
2011 & 25 & $13(52 \%)$ & $11(44 \%)$ & - & - & $1(4 \%)$ & - \\
2012 & 48 & $15(31 \%)$ & $25(52 \%)$ & $8(17 \%)$ & - & - & - \\
2013 & 40 & $18(45 \%)$ & $12(30 \%)$ & $2(5 \%)$ & $8(20 \%)$ & - & - \\
2014 & 48 & $25(52 \%)$ & $11(23 \%)$ & $3(6 \%)$ & $9(19 \%)$ & - & - \\
2015 & 30 & $15(50 \%)$ & $6(20 \%)$ & $5(17 \%)$ & $4(13 \%)$ & - & - \\
2016 & 29 & $21(73 \%)$ & $7(24 \%)$ & $1(3 \%)$ & - & - & - \\
Total & 334 & $161(48 \%)$ & $106(32 \%)$ & $29(9 \%)$ & $35(10 \%)$ & $3(1 \%)$ & - \\
\hline
\end{tabular}


Table 3 Distribution of level 4 and level 5 abstracts according to radiological technique used. Note that when more than one technique was used, one point was assigned to each of the technique involved. For this reason, the sum of the values reported in this table is higher than those reported in Table 2

\begin{tabular}{lcc}
\hline Technique & \multicolumn{2}{c}{ Level of modified Thornbury scale } \\
\cline { 2 - 3 } & 4. Therapeutic impact & 5. Patient outcomes \\
\hline Ultrasound & 18 & 1 \\
Magnetic resonance imaging & 3 & 1 \\
Computed tomography & 6 & $3 *$ \\
Interventional procedures (US + CT + x-ray) & 30 & 1 \\
Others (tomosynthesis, PET-MRI, PET-CT, fluoroscopy, etc.) & 4 & 2 \\
\hline
\end{tabular}

*Level 5 abstracts were related to interventional procedures past, having probably been considered lower than that in other life-threatening conditions. However, there are quite a few areas of musculoskeletal radiology that deserve special attention. One topic of high interest is certainly sarcopenia, which is a chronic condition characterized by progressive loss of skeletal muscle mass typically occurring with aging [11]. The clinical implication of this condition is tremendous, as it has been estimated to affect over 32 million people in the European Union by 2045, with $22.3 \%$ prevalence among elderly. Sarcopenia leads both to muscle weakness (and in turn to increased fracture risk) and increased morbidity and mortality in patients undergoing surgery, thus representing a high societal burden. In this setting, radiological research has the chance of playing a major role, especially in finding a reliable, non-invasive method for opportunistic screening of this silent disease [12] with both conventional and non-conventional methods [13]. Another very important field of action is represented by osteoarthritis, affecting more than 24 million people in the USA with prevalence increasing with aging population. Patients do not die from osteoarthritis, but joint pain, which is the most common symptom, leads to major disability, reduced mobility, and ultimately an increase of major cardiovascular events [14]. In this setting, musculoskeletal radiology may play a central role, finding quick and inexpensive methods to detect joint damage even before it becomes clinically evident. These are only two examples of how musculoskeletal radiology may really make the difference in patients' outcome.

The spectrum of ESSR research to date demonstrates a need to balance technical and "impact" research, especially when financial and human resources are limited. We are aware that high-level studies are time- and resourceconsuming when compared with simpler investigations, but they have the potential to put radiology at the upper end of quality in evidence-based practice. However, the traditional concept that randomized controlled trials are one of the best methods to yield valid scientific evidence is being questioned [15] and we should keep an open mind.

Current European financial limitations are likely to restrict new technology and the radiology research may be better directed to the study of therapeutic impact, patient outcome, and social impact in an environment where there is a reduction in provision of new techniques. There is the potential to arrange and coordinate fixed protocol long-term studies of technical advances. The European Community has assigned some resources to the assessment of "the effectiveness of existing healthcare interventions in the adult population" through the Horizon 2020 Working Programme [16]. The goal of the European Commission is to address many challenges to society through more effective prevention, diagnosis, and treatment. Thus, the ESSR Research Committee intends to encourage research with potential to influence treatment, patient outcome, and social impact.

Table 4 Overview of abstracts related to interventional procedures

\begin{tabular}{|c|c|c|c|c|c|c|c|}
\hline & \multicolumn{7}{|c|}{ Level of modified Thornbury scale } \\
\hline & $\begin{array}{l}\text { Total number of } \\
\text { abstracts }\end{array}$ & $\begin{array}{l}1 \text { Technical } \\
\text { performance }\end{array}$ & $\begin{array}{l}\text { 2.Diagnostic } \\
\text { performance }\end{array}$ & $\begin{array}{l}\text { 3.Diagnostic } \\
\text { impact }\end{array}$ & $\begin{array}{l}\text { 4.Therapeutic } \\
\text { impact }\end{array}$ & $\begin{array}{l}\text { 5. Patient } \\
\text { outcomes }\end{array}$ & $\begin{array}{l}\text { 6. Social } \\
\text { impact }\end{array}$ \\
\hline $\begin{array}{l}\text { Interventional } \\
\text { procedures }\end{array}$ & 73 & $15(21 \%)$ & $9(12 \%)$ & $16(22 \%)$ & $30(41 \%)$ & $3(4 \%)$ & - \\
\hline
\end{tabular}


Acknowledgments Alberto Stefano Tagliafico is Chair of the Research Committee of the ESSR up to 2019. Luca Maria Sconfienza was Chair of the Research Committee of the ESSR from 2013 to 2016. David Wilson was Chair of the Research Committee of the ESSR from 2010 to 2013.

Authors acknowledge the work of Bianca Bignotti and Federica Rossi (University of Genova, Italy).

Funding The authors state that this work has not received any funding.

\section{Compliance with ethical standards}

Guarantor The scientific guarantor of this publication is Alberto Stefano Tagliafico.

Conflict of interest The authors of this manuscript declare no relationships with any companies, whose products or services may be related to the subject matter of the article.

Statistics and biometry No complex statistical methods were necessary for this paper.

Informed consent Approval from the institutional committee was not required because this study does not involve human subjects.

Ethical approval Institutional Review Board approval was not required because this study does not involve human subjects.

\section{Methodology}

- observational

- multicenter study

\section{References}

1. European Society of Radiology (ESR) (2015) The consequences of the economic crisis in radiology. Insights Imaging 6(6):573-577

2. Grady D, Redberg RF (2010) Less is more: how less health care can result in better health. Arch Intern Med 170(9):749-750

3. Fisher ES, Wennberg DE, Stukel TA, Gottlieb DJ, Lucas FL, Pinder EL (2003) The implications of regional variations in Medicare spending. Part 2: health outcomes and satisfaction with care. Ann Intern Med 138(4):288-298
4. Thornbury JR (1994) Why should radiologists be interested in technology assessment and outcomes research? AJR Am J Roentgenol 163(5):1027-1030

5. Thornbury JR, Eugene W (1994) Caldwell lecture. Clinical efficacy of diagnostic imaging: love it or leave it. AJR Am J Roentgenol 162(1):1-8

6. European Society of Musculoskeletal Radiology (ESSR). www. essr.org. Accessed June 2018

7. Burstein D, Mitchell R, Gray ML (2019) Strategically guiding research through careful consideration of the path to impact. Radiology 290(1):5-7

8. Medina LS, Blackmore CC (2006) Evidence-based imaging, 1st edn. Springer, New York, p 18

9. Sardanelli F, Hunink MG, Gilbert FJ, Di Leo G, Krestin GP (2010) Evidence-based radiology: why and how? Eur Radiol 20(1):1-15

10. Hollingworth W, Jarvik JG (2007) Technology assessment in radiology: putting the evidence in evidence-based radiology. Radiology 244:31-38

11. Messina C, Maffi G, Vitale JA, Ulivieri FM, Guglielmi G, Sconfienza LM (2018) Diagnostic imaging of osteoporosis and sarcopenia: a narrative review. Quant Imaging Med Surg 8(1):8699. https://doi.org/10.21037/qims.2018.01.0

12. Sconfienza LM (2018) Sarcopenia: ultrasound today, smartphones tomorrow? Eur Radiol 29(1):1-2. https://doi.org/10.1007/s00330018-5833-0

13. Rossi F, Valdora F, Barabino E, Calabrese M, Tagliafico AS (2018) Muscle mass estimation on breast magnetic resonance imaging in breast cancer patients: comparison between psoas muscle area on computer tomography and pectoralis muscle area on MRI. Eur Radiol. https://doi.org/10.1007/s00330-018-5663-0

14. Aleksandra T, Ahmad KA, Martin E (2019) Cause-specific mortality in osteoarthritis of peripheral joints. Osteoarthritis Cartilage S1063-4584(19):30851-30859. https://doi.org/10.1016/j.joca. 2019.02.793

15. Wallis CJD, Detsky AS, Fan E (2018) Establishing the effectiveness of procedural interventions: the limited role of randomized trials. JAMA. https://doi.org/10.1001/jama.2018.16329

16. https://ec.europa.eu/eip/ageing/funding/health-programme/ comparing-effectiveness-existing-healthcare-interventions-adultpopulation_en. Accessed on June 2016

Publisher's note Springer Nature remains neutral with regard to jurisdictional claims in published maps and institutional affiliations. 